\title{
Computer Simulation and Control of a Theoretical Coagulation pH System in Water Treatment
}

\author{
Shadrack Fosu ${ }^{1 *}$, Darlington Jerry Yawson², Clement Owusu ${ }^{1}$ \\ ${ }^{1}$ University of Mines and Technology, Tarkwa, 237, Ghana \\ ${ }^{2}$ Zeal Environmental Technologies Limited, No.4 Beachmasters Drive, Harbour Access Road, Takoradi, Ghana \\ Email: ${ }^{1}$ sfosu@umat.edu.gh, ${ }^{2}$ yawsondarlingtonjerry@gmail.com
}

\begin{abstract}
Coagulation is an important process in water treatment operations. Inorganic coagulants such as aluminium salts consume alkalinity and may necessitate the addition of alkaline agent such as lime during coagulation. The $\mathrm{pH}$ required for coagulation is very critical. Particularly, aluminium salts serving as a basis for this work are most effective around a pH range of 5.5-6.5. It is therefore vital to attain this $\mathrm{pH}$ after the coagulant has been added. In this study, a typical coagulation $\mathrm{pH}$ control application called CoagiT has been developed. CoagiT seeks to maintain the optimum $\mathrm{pH}$ necessary for effective coagulation in water treatment. The application was developed particularly for application in Ghana using instrumentation and control principles and Visual Basic (VB) programming algorithms. This application can enhance learning by integrating the theoretical cogitation of control process with tactile nature of the plant. The application can operate in both closed-loop manual and automatic control modes. In the manual mode, when the measured $\mathrm{pH}$ value of the coagulation water is not equal to the set point $\mathrm{pH}$, the application alerts an operator (by sounding an alarm) and suggests the percentage by which the lime supply rate should be adjusted to achieve the set point. In the automatic mode, the application automatically adjusts the lime supply rate to achieve the set point $\mathrm{pH}$ with the help of a $\mathrm{pH}$ transmitter and a $\mathrm{pH}$ indicating controller. CoagiT may be a useful simulation tool to provide user graphical windows environment in reducing the problems associated with ineffective coagulation due to improper $\mathrm{pH}$ control during water treatment.
\end{abstract}

Keywords: coagulation, pH, computer simulation, visual basic programming, process control, water treatment

\section{Introduction}

Coagulation is an important process in water treatment operations. It forms the basis of the entire water treatment process and as such, it can have a significant impact (positive or negative) on the performance of downstream process units [1]. Coagulation involves the destabilisation and subsequent aggregation of suspended and colloidal particles from raw water owing to the addition of chemical coagulants [2]. Effective coagulation is vital to achieve operational efficiency of water treatment plants, compliance with standards set by regulatory agencies and provision of consistent potable water for consumption. Otherwise, the water treatment process will result in wastage of expensive chemicals, poor floc formation, less efficient filtration and health hazards to final consumers [3]. The key issue about the process is that, coagulants functions effectively only within a specified $\mathrm{pH}$ range hence, the efficacy of the coagulation process depends on proper control of raw water $\mathrm{pH}[4]$.

Coagulation is effective within a feed water $\mathrm{pH}$ of 5.5-6.5 for alum salts and $\mathrm{pH}$ of 4.5-5.5 for ferric chloride salts [5]. Addition of inorganic coagulants to feed water mostly consume the alkalinity of the feed water and hence decreases the $\mathrm{pH}$ of the feed water [6]. In order to counter-act the effect of coagulants on $\mathrm{pH}$ and ensure effective coagulation, most water treatment facilities use $\mathrm{pH}$ control methods such as the addition of lime to adjust and maintain the $\mathrm{pH}$ to the optimal range [6].

Adjusting the lime feed rate to achieve the optimal $\mathrm{pH}$ range or set point for effective coagulation is difficult and exhausting and often involves the use of the trial and error approach, which is particularly the case in some water treatment facilities in Ghana. As a result, a more reliable, accurate and efficient control system based on a computer programming software is needed. This software together with analytical sensors should be able to automatically adjust the $\mathrm{pH}$ of the feed water to its set point by 
adjusting and controlling the lime dose rate. Also, it should be able to alert operators to dose in the correct amount of lime that would adjust the $\mathrm{pH}$ to the set point when operating in the manual mode. Most water treatment facilities in Ghana, however, do not have any control system for $\mathrm{pH}$ control during coagulation $[7]$.

This study therefore, seeks to enhance process control education with simulation of a coagulation $\mathrm{pH}$ control system, to control the $\mathrm{pH}$ of the feed water during coagulation in water treatment systems, by adopting and modifying the Process Flow Diagram (PFD) shown in Figure 1 using Visual Basic programming language.

\section{Background}

\subsection{Chemical Coagulation and pH Control}

Most metal coagulants generate an acidic environment when introduced in water [8], and therefore their addition consumes alkalinity. For example, when alum is used as a coagulant, it hydrolyses and forms aluminium hydroxide floc by reacting with the natural alkalinity (usually consists of bicarbonate), as expressed by Equation 1, with the insoluble products (precipitates) in italics [9]:

$$
\mathrm{Al}_{2}\left(\mathrm{SO}_{4}\right)_{3} \cdot 14 \mathrm{H}_{2} \mathrm{O}+6 \mathrm{HCO}_{3}^{-} \rightleftharpoons 2 \mathrm{Al}(\mathrm{OH})_{3}(s)+6 \mathrm{CO}_{2}+14 \mathrm{H}_{2} \mathrm{O}+3 \mathrm{SO}_{4}^{2-}
$$

Each mole of hydrated aluminium sulphate added consumes six (6) moles of alkalinity and produces six mole of carbon dioxide. The above reaction shifts the carbonate equilibrium and decreases the $\mathrm{pH}$. Nevertheless, as long as sufficient alkalinity is present and $\mathrm{CO}_{2}(\mathrm{~g})$ is allowed to evolve, the pH is not drastically reduced and is generally not an operational problem. Bourke et al. $[9]$ indicated that, a $1 \mathrm{mg} / \mathrm{L}$ dose of alum reacts with $0.53 \mathrm{mg} / \mathrm{L}$ of alkalinity expressed as $\mathrm{CaCO}_{3}$. Therefore, coagulant addition into waters with low alkalinity may produce sulphuric acid (Equation 2) leading to the consumption of all the alkalinity available in the water and reducing the $\mathrm{pH}$ to a value too low for effective coagulation $[6,8]$ :

$$
\mathrm{Al}_{2}\left(\mathrm{SO}_{4}\right)_{3} \cdot 14 \mathrm{H}_{2} \mathrm{O} \rightleftharpoons 2 \mathrm{Al}(\mathrm{OH})_{3}(s)+8 \mathrm{H}_{2} \mathrm{O}+3 \mathrm{H}_{2} \mathrm{SO}_{4}^{2-}
$$

In such a situation, additional alkali such as hydrated lime $\left\{\mathrm{Ca}(\mathrm{OH})_{2}\right\}$, is added to supply the water with the necessary alkalinity required to produce the aluminium hydroxide floc needed for effective coagulation. This can be expressed by Equation 3 .

$$
\mathrm{Al}_{2}\left(\mathrm{SO}_{4}\right)_{3}+3 \mathrm{Ca}(\mathrm{OH})_{2} \rightleftharpoons 2 \mathrm{Al}(\mathrm{OH})_{3}+\mathrm{CaSO}_{4}
$$

The metal hydroxide flocs formed with the use of inorganic coagulants (such as alum) are known to be insoluble over relatively narrow bands of $\mathrm{pH}$, which may vary with the source of the raw water $[6,9]$. Therefore, the $\mathrm{pH}$ at which coagulation occurs is the most important parameter for proper coagulation performance $[6,10]$. The latter implies that $\mathrm{pH}$ control (In a real plant it is not only the process control, but the parameter of concern in this work) is necessary for effective coagulation. Proper $\mathrm{pH}$ control does not only help in efficient removal of turbidity and colour, but also help to maintain satisfactory minimum levels of dissolved residual aluminium in the clarified water [9]. Studies by $\mathrm{Hu}$ et al. [11] also indicated that proper $\mathrm{pH}$ control during coagulation is essential to:

a) Increase the removal of natural organic matter (NOM) from raw water when using alum;

b) Improve the coagulation process by regulating metal species distributions;

c) Significantly improve the coagulation efficiency of $\mathrm{AlCl}_{3}$ in eutrophic waters;

d) Reduce wastage of chemicals;

e) Obtain good floc formation;

f) Increase efficient filtration; and

g) Reduce health hazards to final consumers.

\subsection{Theory and Principle Behind CoagiT}

The software was developed by modifying and simulating the Process Flow Diagram (PFD) of the coagulation pH control system shown in Figure 1. In the PFD shown, raw water (influent) and coagulant flow into a mixing chamber containing a motor-controlled mixing agitator for rapid mixing of solution. 
The solution moves into a contact zone with a $\mathrm{pH}$ transmitter (AT) to measure the $\mathrm{pH}$ of the solution and transmit this measured $\mathrm{pH}$ in its equivalent electrical signal (4-20 mA) to a $\mathrm{pH}$ indicating controller (AIC). The $\mathrm{pH}$ indicating controller compares the signal from the $\mathrm{pH}$ transmitter to a set point (SP) within the AIC and sends a control signal based on the difference between the measured signal and the set point (i.e. the error) to a variable speed drive of a conveyer to adjust its speed, this subsequently controls the lime feed rate into the mixing chamber. This simple feedback mechanism is the fundamental framework guiding the operation of the simulation software.

To consider how this feedback control strategy could be implemented, a block diagram (closed loop control) for the coagulation $\mathrm{pH}$ control system is shown in Figure 2. For the coagulation pH under feedback control (Figure 1), the $\mathrm{pH} y(\mathrm{~s})$ is controlled and the lime reagent flow rate $\mathrm{r}_{2}$ is adjusted using proportional control. The operation of this feedback control system can be summarised as follows:

I. Analyser and transmitter: The mixing tank $\mathrm{pH}(\mathrm{y}(\mathrm{s}))$ is measured by an analyser and then the measurement is converted to a corresponding electrical current signal by a transmitter.

II. Feedback control: The controller performs three distinct calculations. First, it converts the actual $\mathrm{pH}$ set point $X_{s p(s)}$ into an equivalent internal signal $i_{s p}$. Second, it calculates an error signal $e(s)$ by subtracting the measured value $y_{m}(s)$ from the set point corresponding signal $i_{s p}$, that is $e(s)=i_{s p}$ $-y_{m}(s)$. Third, controller output $c(s)$ is calculated from the proportional control law.

III. Lime conveyor motor: The controller output $c(s)$ in this case an electrical current signal is sent to the conveyor motor (lime reagent conveyor motor) to adjust the percentage speed of the conveyor, which affects flow rate $r_{2}(s)$.

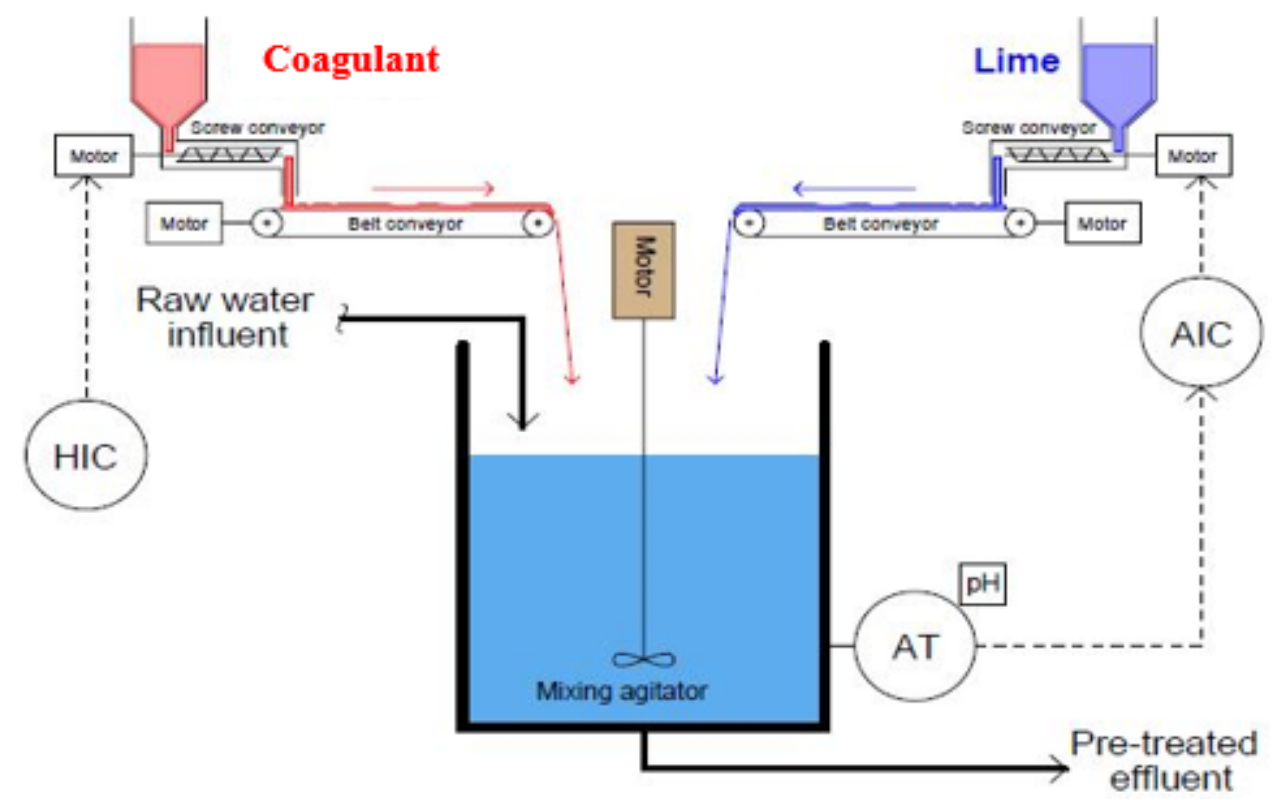

Figure 1. PFD of a coagulation $\mathrm{pH}$ control system [12]

The mathematical expression or the transfer function showing the closed loop response (Figure 2) is given by Equation 4:

$$
y(s)=\frac{G a(s) G c(s) G p(s) G v(s)}{1+G c(s) G m(s) G p(s) G v(s)} \cdot X s p(s)+\frac{r_{1}(s) G p(s)}{1+G c(s) G m(s) G p(s) G v(s)}+\frac{D G g(s) G p(s)}{1+G c(s) G m(s) G p(s) G v(s)}
$$

where, $G a(s)$ is the transfer function of analyser calibrator in the controller, $G c(s)$ is the transfer function of the controller, $G v(s)$ is the transfer function of the lime conveyor motor, $G g(s)$ is the transfer function of coagulant reagent conveyor motor, $G p(s)$ is the transfer function of the process in the mixing tank, $G m(s)$ is the transfer function of the senor (feedback) and $f(s)$ is the total flow mixture of raw water and coagulant before addition of lime going into the mixing tank. 


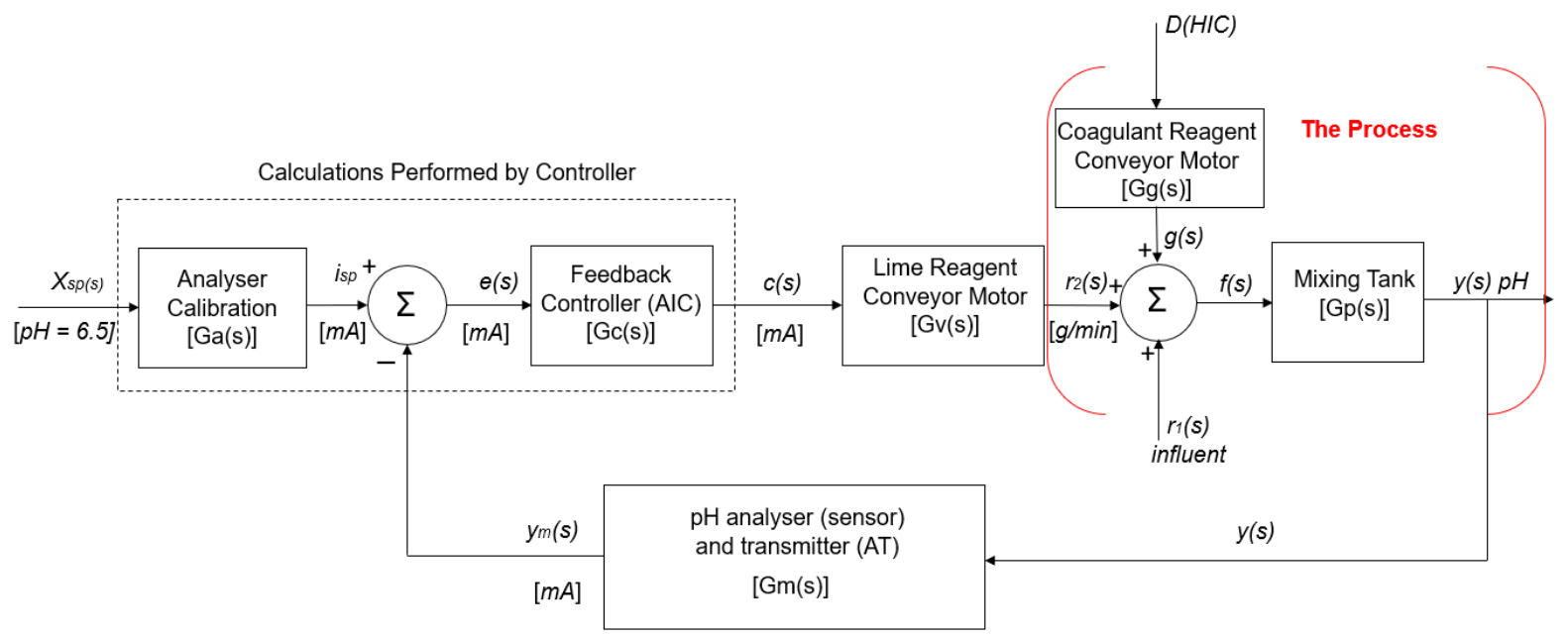

Figure 2. Block diagram for the coagulation feedback control system in Figure 1

\section{$3 \quad$ Resources and Method Used}

\subsection{Designing and Testing of CoagiT}

CoagiT was developed mainly to measure the coagulation $\mathrm{pH}$ of water and ensure that the $\mathrm{pH}$ is within the set point by adjusting the lime dose rate. This ensures effective coagulation and eliminates the problems (poor floc formation, less efficient filtration, health hazards to final consumers and noncompliance with government agencies) associated with ineffective coagulation. CoagiT operates using the equations and interpolations outlined below.

\subsubsection{Measured signal-measured value conversion}

Equation 5 was used in the programme to convert the measured signal (in milli-amperes) of the analytical transmitter to a measured $\mathrm{pH}$ value $[7,12]$. This allows for the comparison of the measured value with the set point.

$$
\mathrm{MV}=\left[\left(\frac{\mathrm{MS}-\mathrm{LRV}_{\mathrm{s}}}{\mathrm{Span}_{\mathrm{s}}}\right) \times\left(\operatorname{Span}_{\mathrm{m}}\right)\right]+\mathrm{LRV}_{\mathrm{m}}
$$

where;

$$
\begin{aligned}
& M V=\text { Measured value } \\
& M S=\text { Measured signal } \\
& \mathrm{LRV}_{\mathrm{s}}=\text { Lower Range Value of the transmitter signal } \\
& \mathrm{Span}_{\mathrm{s}}=\text { Span of transmitter signal } \\
& \mathrm{Span}_{\mathrm{m}}=\text { Span of measurement } \\
& \mathrm{LRV}_{\mathrm{m}}=\text { Lower Range Value of measurement }
\end{aligned}
$$

\subsubsection{Error calculation}

CoagiT uses the difference between the measured value and the set point to adjust the lime feed rate. This difference is called the error and Equation 6 shows how it is calculated [7].

$$
\text { Error }=|\mathrm{SP}-\mathrm{MV}|
$$

where;

$$
\begin{aligned}
& \mathrm{SP}=\text { Set point } \\
& \mathrm{MV}=\text { Measured value }
\end{aligned}
$$

\subsubsection{Motor speed adjustment}

The speed of the lime conveyor motor is adjusted using Equation 7. 


$$
\text { Speed }(\%)=\frac{|\mathrm{SP}-\mathrm{MV}|}{\mathrm{SP}} \times 100
$$

where;

$$
\begin{aligned}
& \mathrm{SP}=\text { Set point } \\
& \mathrm{MV}=\text { Measured value }
\end{aligned}
$$

\subsubsection{Motor speed-lime flow rate conversion}

Each motor speed calculated corresponds to a given flow rate of the lime. Equation 8 was used to convert the motor speed (in percentage) to the corresponding lime feed rate (in grams per minute).

$$
L F R=\left[\left(\frac{\text { Speed-LRV }_{\text {speed }}}{\text { Span }_{(\text {speed })}}\right) \times\left(\operatorname{Span}_{L F R}\right)\right]+\operatorname{LRV}_{\text {LFR }}
$$

where;

$\mathrm{LFR}=$ Lime feed rate

$\mathrm{LRV}_{\text {speed }}=$ Lower Range Value of the motor speed

$\mathrm{LRV}_{\mathrm{LFR}}=$ Lower Range Value of the lime feed rate

Span $_{(\text {speed })}=$ Span of the motor speed

$\operatorname{Span}_{(\mathrm{LFR})}=$ Span of lime feed rate

\subsection{Designing of CoagiT}

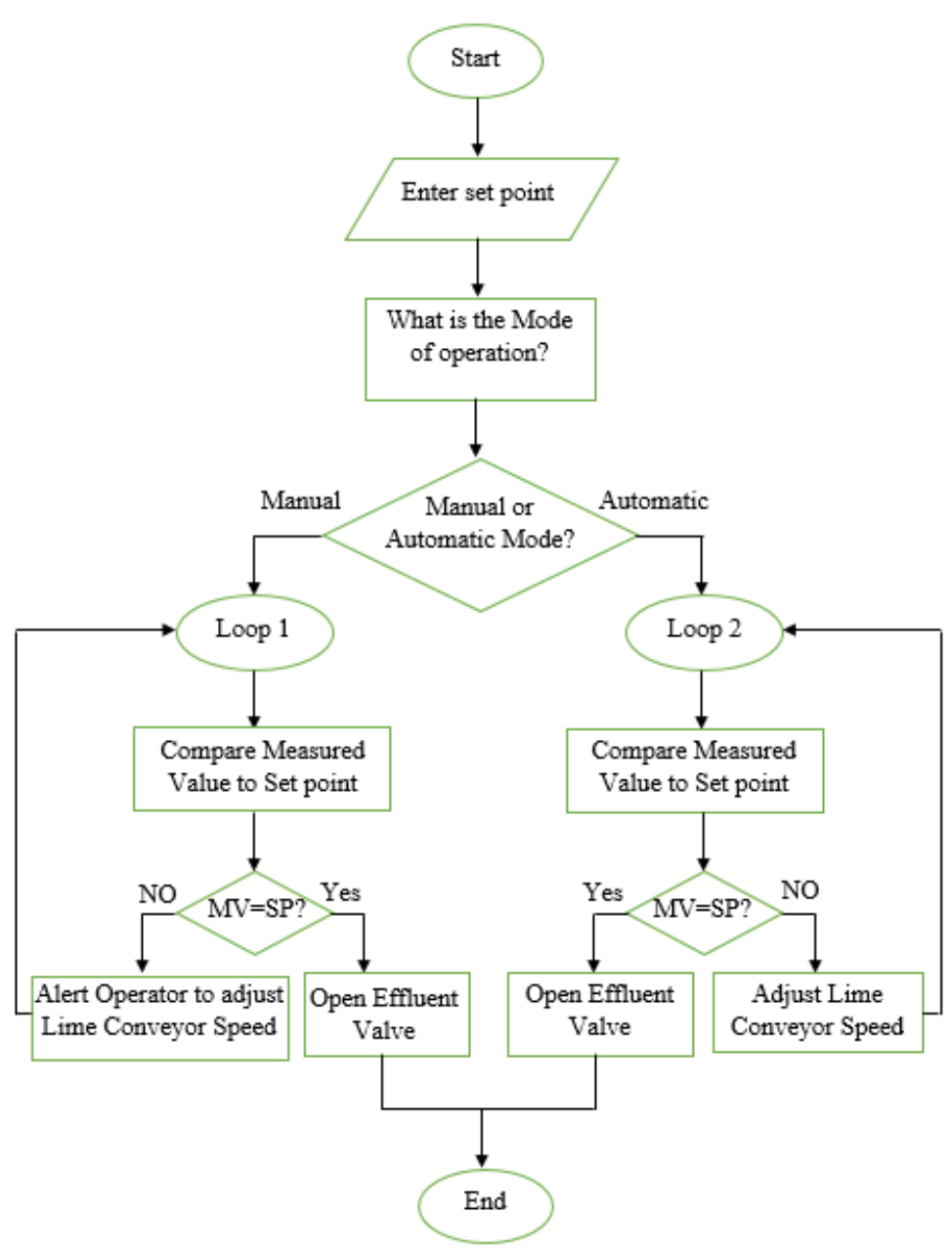

Figure 3. Logic flowchart of CoagiT 
The designing phase in the development of CoagiT covered two main areas. They are:

1) Design of flowchart; and

2) Development of graphical user interface (GUI) of CoagiT.

\subsubsection{Logic flowchart design}

To determine graphically the logical steps involved in the execution of CoagiT, a standard flowchart was designed using standard logic flowchart symbols as shown in Figure 3.

\subsubsection{Development of Graphical User Interface (GUI) of CoagiT}

The GUI of CoagiT consist mainly of a user control section and a simulation section. The user control section was developed using Visual Basic controls such as; buttons, textboxes and radio buttons. The simulation section was also developed by using Visual Basic controls such as progress bars and track bars. Other Visual Basic controls such as labels, group boxes and the picture box found on the GUI were added to give information about the system to users.

\subsection{Coding of CoagiT}

After designing CoagiT's GUI and logic flowchart of the system, codes were written with Visual Basic (Visual Studio 2012) to bring the programme to operation. Declaration statements, conditional statements (such as if-then statements) and mathematical functions are some elements that constituted the codes. In effect, about four hundred (400) lines of programming codes were used in building CoagiT.

\subsection{Debugging and Testing of CoagiT}

Debugging of CoagiT was carried out to detect and correct errors in logic and syntax that were associated with running the programme. CoagiT was also tested using both alpha and beta testing mechanisms. The alpha testing was carried out by going through all the code lines to ensure that the correct syntax of Visual Basic was used. This was carried out during the coding section. Beta testing was also carried out to ensure that the programme responds and operates effectively as planned. CoagiT was also run on computers with different operating systems to test how it operates on these systems. Through the test, it was found out that, CoagiT operates best on Windows 7, 8 and 10 but does not run on Apple Macintosh operating systems and Android operating systems.

\section{Results and Discussion}

\subsection{Operation of CoagiT}

CoagiT measures the $\mathrm{pH}$ of the solution upon the addition of the coagulant. This measured $\mathrm{pH}$ is normally below the set point and as such the application triggers the addition of lime to the solution (by adjusting the speed of the lime conveyor motor) to bring the $\mathrm{pH}$ back to the set point. CoagiT has options to operate either in the manual mode (closed-loop, manual control) or in the automatic mode (closed-loop, automatic control). When operating in the manual mode (i.e. in the absence of a $\mathrm{pH}$ indicating controller), CoagiT has been designed to accept $\mathrm{pH}$ measurements from a transmitter and compare it with the set point. If there are any deviations, it triggers an alarm to alert plant operators of the possible deviation and as well suggest to plant operators the percentage by which the speed of the lime conveyor motor be adjusted to obtain the set point. Plant operators can adjust the speed of the lime conveyor motor from the application until the required coagulation $\mathrm{pH}$ is achieved.

In the automatic mode, CoagiT accept measurements from a transmitter, compares it with the set point and adjusts the speed of the lime conveyor motor automatically depending on the measured value using the $\mathrm{pH}$ indicating controller. This ensures that the optimum coagulation $\mathrm{pH}$ is achieved.

\subsection{Graphical User Interface (GUI) of CoagiT}

The Graphical User Interface (GUI) of CoagiT was designed in such a way, that it is simple and easy to 
operate. It is made up of user controls and a simulation section (Figure 4). The simulation section consists of controls (such as the progress bar) to show the flow of raw water (influent) into the system and coagulated water out of the system. When CoagiT is running, the progress bar depicts the flow of water through the system with a green colour code. The simulation section also has radio buttons to allow/restrict the flow of water out of the system. User controls found on the GUI of CoagiT accept inputs or actions from users to function. Other controls such as labels and the picture box found on the GUI provides information about the system to users. Figure 4 below shows the Graphical User Interface (GUI) of CoagiT when the process has not started running.

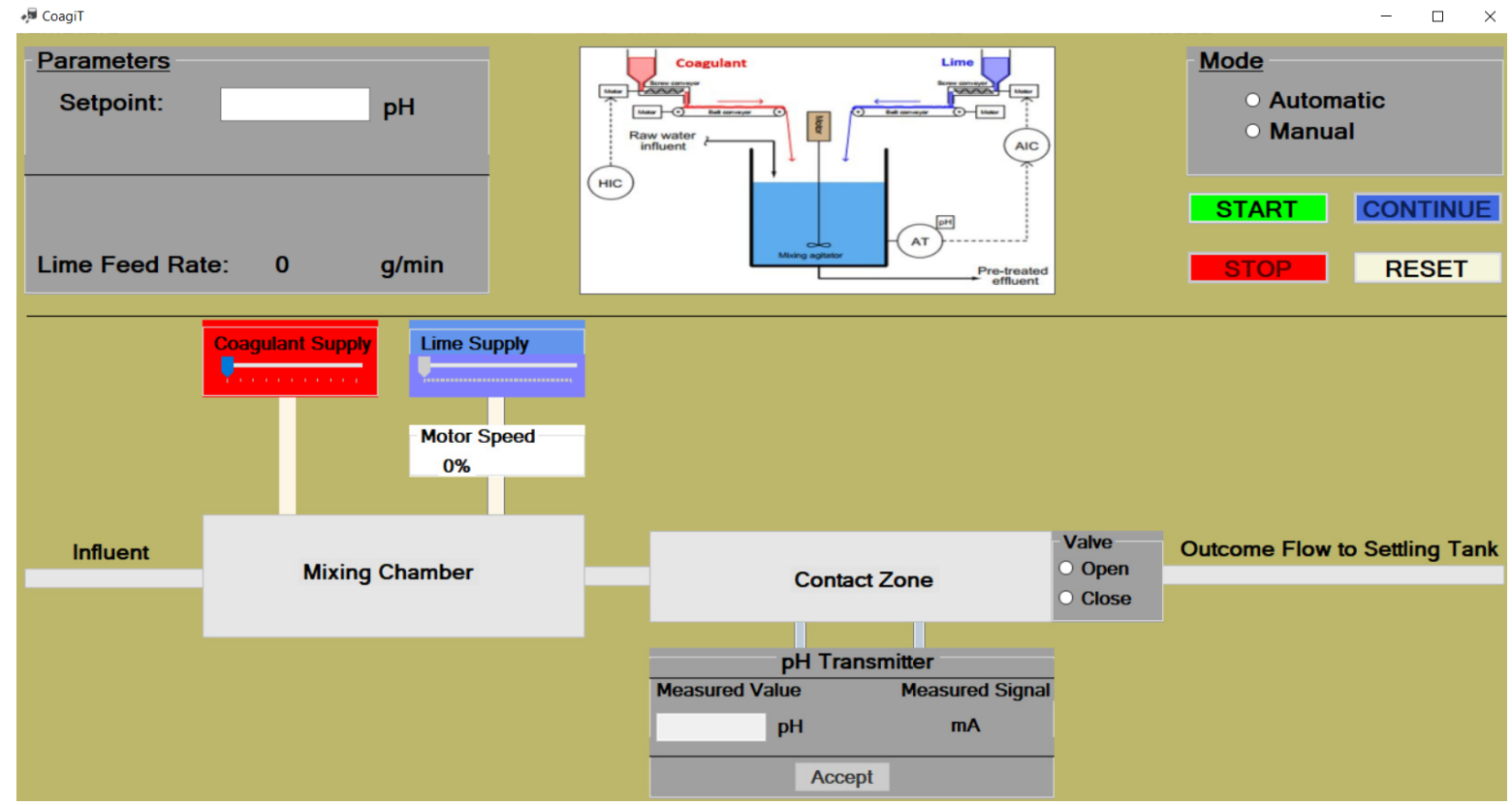

Figure 4. GUI of CoagiT after Loading

\subsubsection{User controls}

User controls found on the GUI of CoagiT include buttons, radio buttons, textboxes and a track bar. The buttons and their uses are explained in Tables 1 below.

\subsection{Demonstration of CoagiT}

During start up, raw water (influent) enters into the mixing chamber (this is seen on the GUI as described in section 4.2). Coagulant is added to the influent in this chamber. The addition of coagulant is confirmed by the change in value of the track bar at the coagulant supply and the change in colour of the discharge pipe carrying the coagulant to the mixing chamber on the GUI (the colour of the discharge pipe changes to red as shown in Figure 5). The solution (raw water and coagulant) then flows into the contact zone where there is a $\mathrm{pH}$ transmitter to measure and record the $\mathrm{pH}$ of the solution. Actions are taken depending on the mode of operation of the programme.

\subsubsection{Automatic mode}

In the automatic mode, when coagulant addition causes the measured $\mathrm{pH}$ value to fall below the set point, the software automatically adjusts the lime feed rate by adjusting the speed of the lime conveyor motor (i.e., the track bar on the lime supply automatically adjust to the desired lime supply rate percentage). This adjustment in lime supply would raise the measured $\mathrm{pH}$ value back to the set point thereby ensuring that the optimum coagulation $\mathrm{pH}$ necessary for effective coagulation is maintained. For example, assuming a set point of $6.5 \mathrm{pH}$ is entered and the measured $\mathrm{pH}$ value after the addition of the coagulant is 1.5 (as illustrated in Figure 5), then an equivalent electrical signal of the measured value (in this case $7.69 \mathrm{~mA}$ ) would be sent to the $\mathrm{pH}$ analytical controller. The $\mathrm{pH}$ analytical controller would 
calculate the error/deviation and send a control signal to adjust the speed of the lime conveyor motor to $77 \%$ (as shown in Figure 6). This adjustment in motor speed would also change the lime feed rate to $669.90 \mathrm{~g} / \mathrm{min}$ as shown in Figure 6. The large deviation of the measured value from the set point resulted in the application adjusting the speed of the lime conveyor motor to as much as $77 \%$ since more of the lime would be needed to bring the measured $\mathrm{pH}$ value back to the set point (as shown in Figure 6).

Table 1. Functions of user controls found on the GUI of CoagiT

\begin{tabular}{ll}
\hline User Control & Purpose \\
\hline Radio Button & CoagiT uses radio buttons to select the mode of operation (automatic or manual) and to show \\
& the state of the outlet valve (i.e. open or close) \\
Textboxes & There are two textboxes on the GUI of CoagiT to accept set point and measured value inputs. \\
& In order to ensure efficient operation of the application, the textboxes are programmed to reject \\
inputs other than numeric characters and also accept inputs that are only in the range of \\
applicability.
\end{tabular}

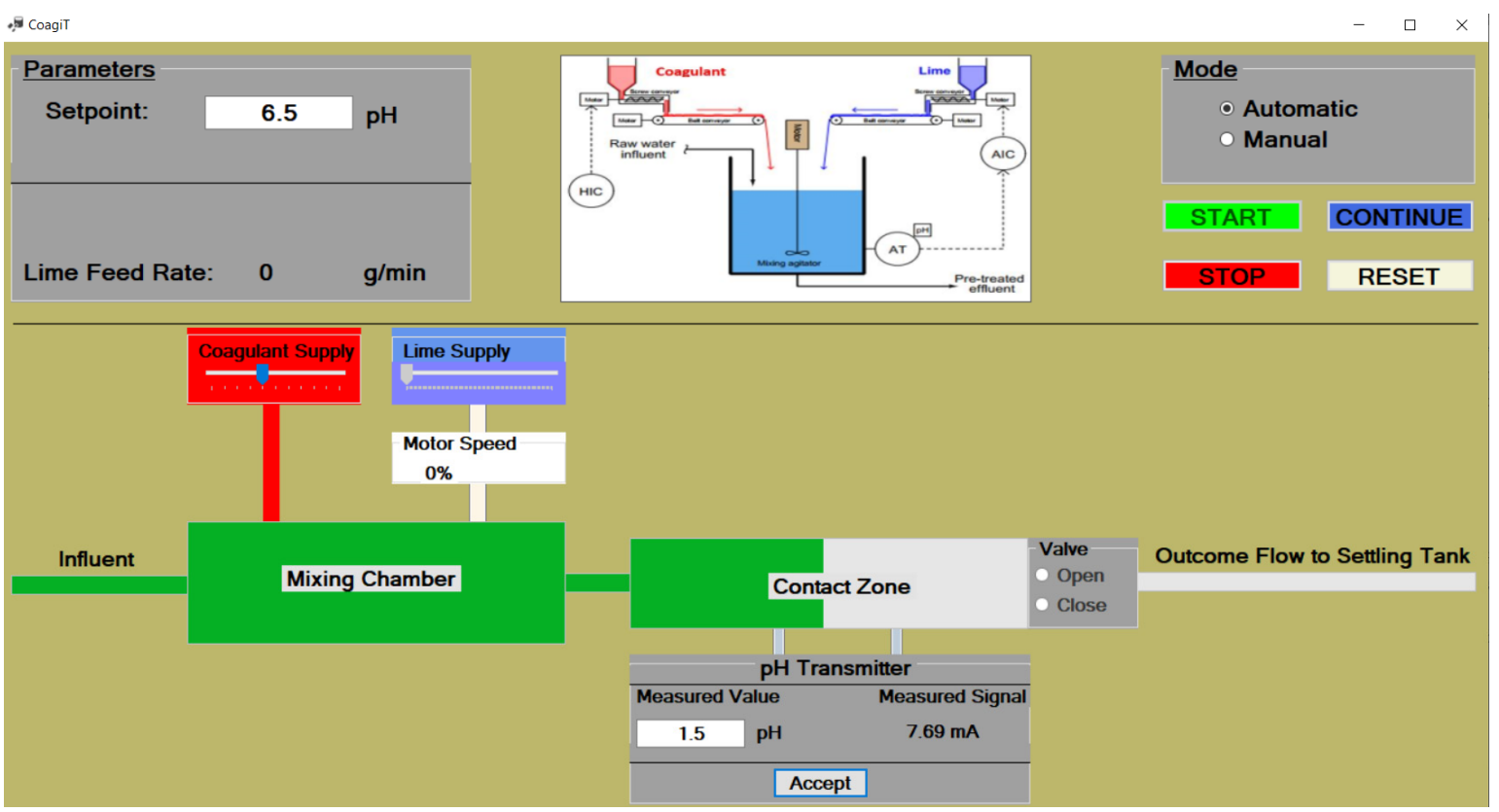

Figure 5. GUI when measured value is $1.5 \mathrm{pH}$ (automatic mode) 


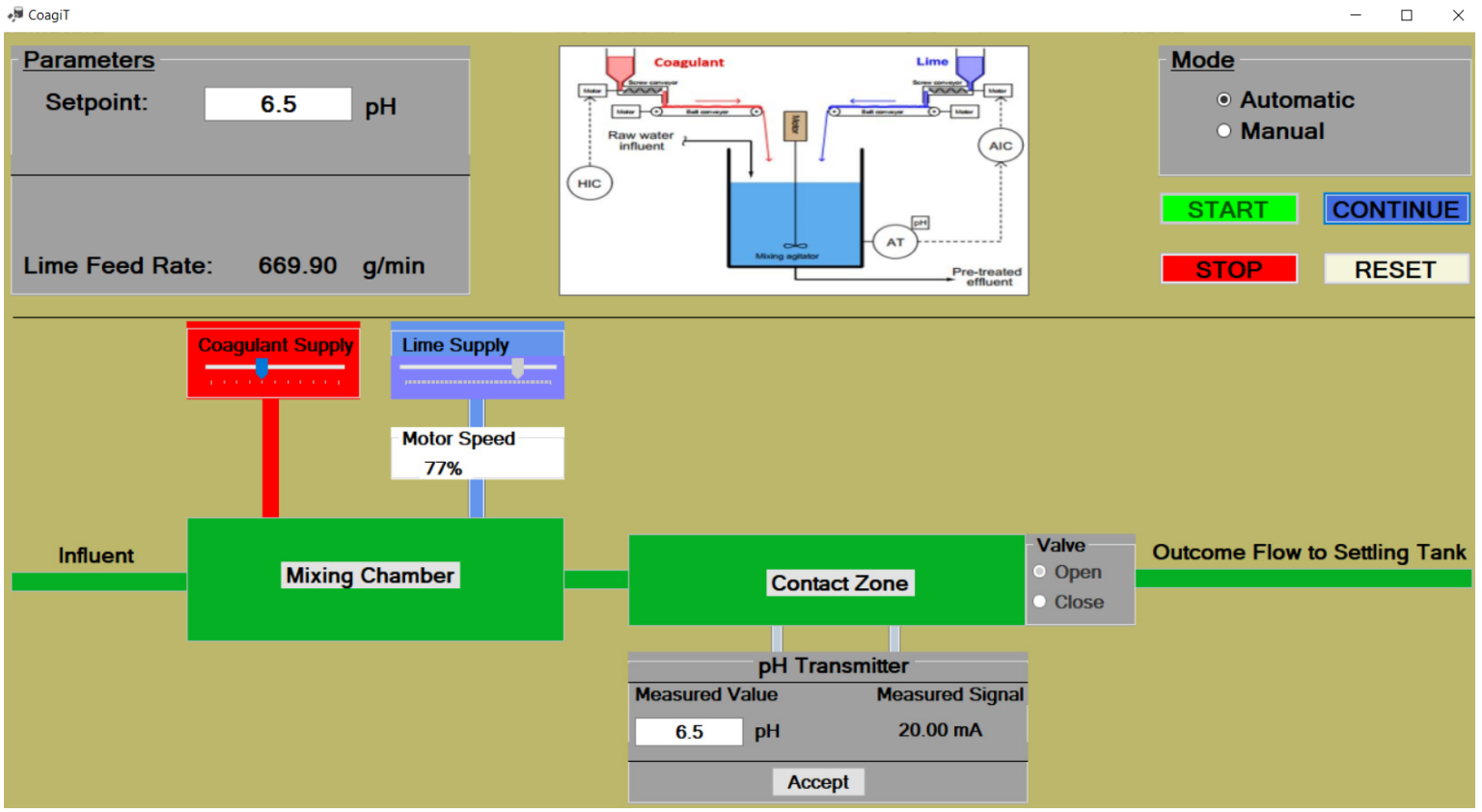

Figure 6. GUI after the lime conveyor motor speed has been adjusted to $77 \%$ (Automatic Mode)

In cases where there is a small deviation of the measured value from the set point, then the speed of the lime conveyor motor would be adjusted in the same magnitude as the deviation. Example, when a set point of $6.5 \mathrm{pH}$ is entered and the measured $\mathrm{pH}$ value recorded after coagulant addition is 6.2 (as shown in Table 2), an equivalent electrical signal of $19.26 \mathrm{~mA}$ would be sent to the $\mathrm{pH}$ analytical controller. The $\mathrm{pH}$ analytical controller would calculate the error/deviation and send a control signal to adjust the speed of the lime conveyor motor and lime feed rate to $5 \%$ and $45.50 \mathrm{~g} / \mathrm{min}$ respectively (as shown in Table 2). These adjustments in motor speed and lime feed rate would bring the measured $\mathrm{pH}$ value back to the set point. When the measured $\mathrm{pH}$ value is equal to the set point $(\mathrm{pH}=6.5)$, the application would automatically open the outlet valve to allow the coagulated water flow to other process unit (such as the settling tank).

Table 2. Application results of CoagiT operating within a set point $\mathrm{pH}$ of 6.5

\begin{tabular}{ccccc}
\hline $\begin{array}{c}\text { Measured Value } \\
(\mathrm{pH})\end{array}$ & $\begin{array}{c}\text { Measured Signal } \\
(\mathrm{mA})\end{array}$ & $\begin{array}{c}\text { Lime Conveyor } \\
\text { Motor Speed }(\%)\end{array}$ & $\begin{array}{c}\text { Lime Feed Rate } \\
(\mathrm{g} / \mathrm{min})\end{array}$ & $\begin{array}{c}\text { Measured Value (pH) } \\
\text { after Lime Addition }\end{array}$ \\
\hline 1.5 & 7.69 & 77 & 669.90 & 6.5 \\
2.5 & 10.15 & 62 & 539.40 & 6.5 \\
4.5 & 15.08 & 31 & 269.70 & 6.5 \\
5.5 & 17.54 & 15 & 130.50 & 6.5 \\
6.2 & 19.26 & 5 & 43.50 & 6.5 \\
6.5 & 20.00 & 0 & 0.00 & 6.5 \\
\hline
\end{tabular}

\subsubsection{Manual mode}

When operating in the manual mode (i.e. in the absence of an analytical indicating controller), the application's main tasks are to:

a) Alert plant operators of any possible deviation of the measured value from the set point by sounding an alarm and reading out a statement to the operators that, "coagulation $\mathrm{pH}$ is not achieved"; and

b) Suggest to operator the percentage by which the speed of the lime conveyor motor should be adjusted to achieve the set point (i.e., the operator will move manually move the track bar on the lime supply to the suggested percentage by the software).

When the $\mathrm{pH}$ transmitter (after the addition of the coagulant) records a $\mathrm{pH}$ value other than the set 
point, a window form will appear on the GUI of the application with a message instructing operators to manually adjust the speed of the lime conveyor motor to a value depending on the magnitude of the error. For example, when a set point of $6.5 \mathrm{pH}$ is entered and the $\mathrm{pH}$ transmitter (after coagulant addition) records a $\mathrm{pH}$ value of 2.0 with a signal of $8.92 \mathrm{~mA}$, the programme would calculate the error and through the pop-up window displayed (serving as indicating controller), it will instruct operators to manually adjust the speed of the lime conveyor motor to $69 \%$ (as shown in Figure 7). After adjusting the lime conveyor motor to $69 \%$, the user then clicks on apply for the process to proceed. As can be seen in Figure 8 , the set point $(\mathrm{pH}=6.5,20 \mathrm{~mA})$ is attained when the speed of the lime conveyor motor was adjusted to $69 \%$.

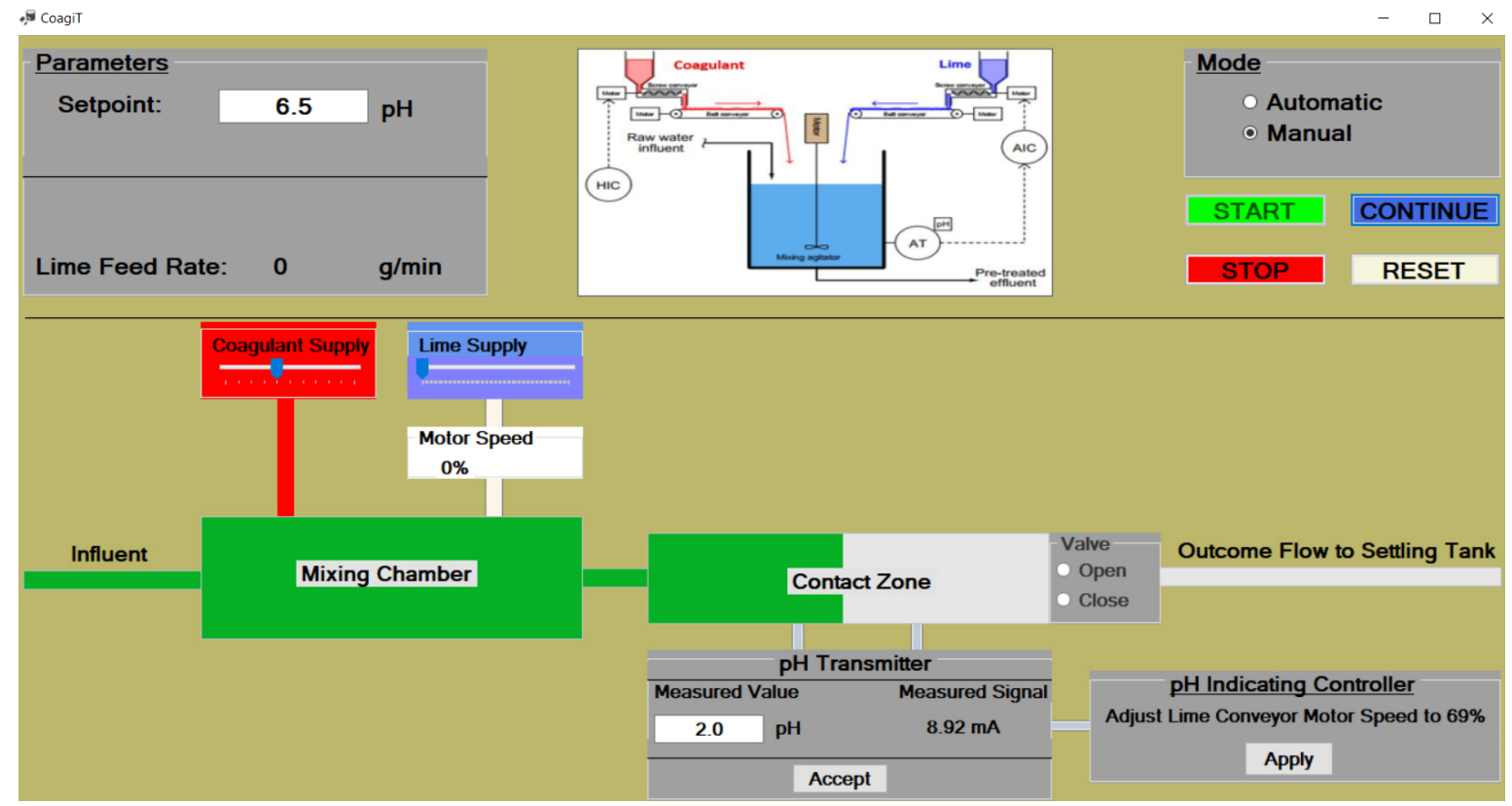

Figure 7. GUI when measured value is $2.0 \mathrm{pH}$ (manual mode)

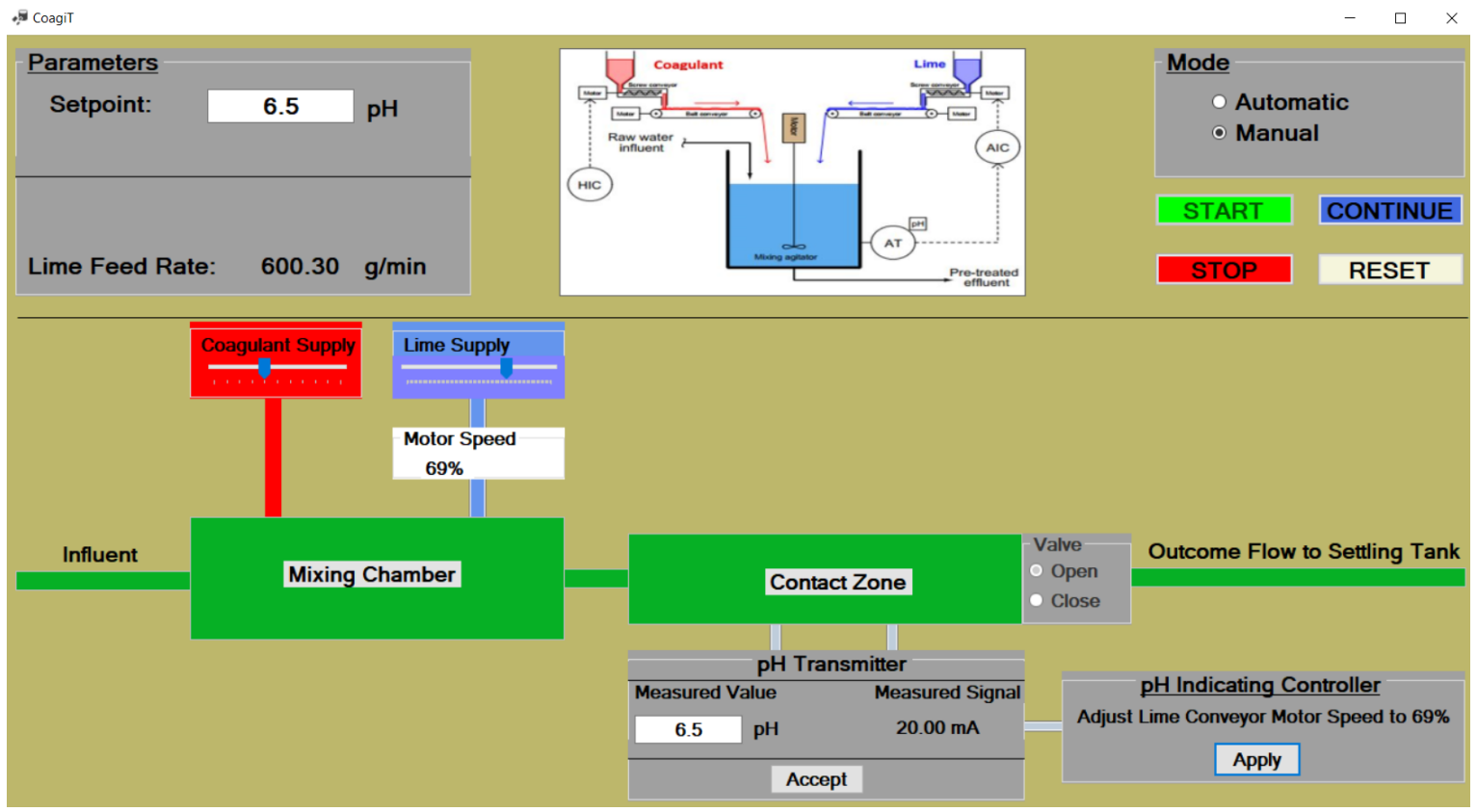

Figure 8. GUI after the lime conveyor motor speed has been manually adjusted to $69 \%$ 


\subsection{Limitations of CoagiT}

VB has only discrete track bars and as a result of this the motor speed only shows integers by rounding up decimals. Also, VB lacks controls that represent the movement of conveyor belts and water tanks. As a result, simulating the PFD in Figure 1 was quite difficult. The application works within the following range of parameters: set-point of $(6.5-8.5) \mathrm{pH}$; and measured value of (0 - Set point) $\mathrm{pH}$.

\section{Conclusions}

A theoretical coagulation pH control simulation application called CoagiT has been successfully developed using process control principles and Visual Basic Programming Language. The main purpose of the application was to ensure effective simulation of coagulation in water treatment by maintaining the desired coagulation $\mathrm{pH}$. The application is capable of operating in closed-loop, automatic control and closed-loop, manual control modes. It measures, alerts and predicts the dosing rates of lime required to maintain the desired coagulation $\mathrm{pH}$ using feedback control mechanisms. It is recommended that, the output of CoagiT should be controlled by standard algorithms in Process Control such as the Proportional-IntegralDerivative (PID) algorithm in controller and smart sensors to manage and eradicate errors effectively.

Acknowledgements. The supports of Environmental and Safety Engineering Department and Minerals Engineering Departments, University of Mines and Technology, Tarkwa - Ghana are highly acknowledged. Ghana Water Company (GWC), Bonsa-Tarkwa is greatly thanked for the tremendous help about water treatment process.

\section{References}

1. Linder, K. and Zachman, B. (2009) "Getting Optimized: Optimize Coagulation and Flocculation", American Water Works Association, Vol. 35, No. 4, pp. 8-9.

2. Bello, O., Hamam, Y., and Djouani, K. (2016), "A comparative study of prediction models for Coagulation process in drinking Water Treatment Plants", Int. Journal of Applied Sciences and Engineering Research, Vol. 5, No. 6, pp. 1-9, ISSN 2277-9442.

3. Cox, C., Fletcher, I. and Adgar, A. (2001), "ANN-based sensing and control in the water industry: A decade of innovation", In Proceedings of the IEEE International Symposium on Intelligent Control, Mexico City, Mexico.

4. Koohestanian, A., Hosseini, M. and Abbasian, Z. (2008), "The separation method for removing of colloidal particles from raw water", American-Eurasian Journal of Agricultural and Environmental Science, Vol. 4, No. 2, pp. 266273.

5. Anon. (2018), "Conventional Treatment", https://iaspub.epa.gov. Accessed: February 4, 2018.

6. Gebbie, P. (2006), "An operator's guide to water treatment coagulants", In 31st Annual QLD Water Industry Workshop - Operations Skills, University Central Queensland - Rockhampton, pp. 14-20.

7. Minkah, P.E., Fosu, S., Ndur, S.A., Asante, E.O., 2018. Computer simulation and modelling of chlorine monitoring and regulation system in water and wastewater treatment, 3 (1), pp. 69-78.

8. Ashery, A.F., Radwan, K. and Rashed, M.I.G. (2011), "The effect of pH control on turbidity and NOM removal in conventional water treatment", In Proceedings of the Fifteen International Water Technology Conference, Alexandria, Egypt, pp. 28-30.

9. Bourke, N., Carty, G., O'Leary, G., Crowe, M., Page, D. (2002), "Water Treatment Manuals-Coagulation, Flocculation \& Clarification", Published by the Environmental Protection Agency, Ireland, pp. 14-19, ISBN: 184095-090-0.

10. BaiChuan, C., BaoYu, G., ChunHua, X., Ying, F., Xin, L. (2009), "Effects of pH on coagulation behaviour and floc properties of Yellow River water treatment using ferric based coagulants", Chinese Science Bulletin, Vol. 55, No. 14, pp. 1382-1387.

11. Hu, C., Liu, H., Qu, J., Wang, D. and Ru, J. (2006), "Coagulation behavior of aluminum salts in eutrophic water: significance of Al13 species and pH control", Environmental science \& technology, pp. 325-331.

12. Kuphaldt, T.R. (2008), "Lessons in Industrial Instrumentation" Creative Commons Attribution/PA Control. Com, pp.491-2512. 